\title{
Twist-Shaped CuO Nanowires as Anode Materials for Lithium Ion Batteries
}

\author{
Hongdong Liu, ${ }^{1}$ Ye Lin, ${ }^{1}$ Zhongli Hu, ${ }^{1}$ Rong Hu, ${ }^{1}$ Haibo Ruan, ${ }^{1}$ and Lei Zhang ${ }^{2}$ \\ ${ }^{1}$ Research Institute for New Materials Technology, Chongqing University of Arts and Sciences, Chongqing 402160, China \\ ${ }^{2}$ College of Life Science, Chongqing Normal University, Chongqing 401331, China
}

Correspondence should be addressed to Lei Zhang; leizhang0215@126.com

Received 21 April 2016; Accepted 8 May 2016

Academic Editor: Gongming Wang

Copyright (C) 2016 Hongdong Liu et al. This is an open access article distributed under the Creative Commons Attribution License, which permits unrestricted use, distribution, and reproduction in any medium, provided the original work is properly cited.

Twist-shaped $\mathrm{CuO}$ nanowires were synthesized by two-step method consisting of solution reaction and then heat treatment. The assynthesized samples were characterized by X-ray diffraction (XRD) and transmission electron microscopy (TEM). When evaluated as anode materials for lithium ion batteries, twist-shaped $\mathrm{CuO}$ nanowires showed a high initial discharge capacity of $983 \mathrm{mAh} \mathrm{g}^{-1}$ and maintained a reversible capacity of $320 \mathrm{mAh} \mathrm{g}^{-1}$ over 50 cycles at the current density of $100 \mathrm{~mA} \mathrm{~g}^{-1}$. Thus, 1D twist-shaped $\mathrm{CuO}$ nanowires provide a new insight into the development of anode materials for next-generation high performance lithium ion batteries.

\section{Introduction}

Rechargeable lithium ion batteries have been considered as the most promising energy storage device for portable electronic devices and electrical vehicles due to their high electromotive force and high energy density [1-4]. Graphite is commonly used as the anode material for commercial lithium ion batteries owning to its natural abundance and low cost $[5,6]$. However, graphite with low capacity of $372 \mathrm{mAh} \mathrm{g}^{-1}$ can not meet the increasing demand for high energy density $[7,8]$. Therefore, it is urgent to explore a novel anode material with high theoretical capacity, such as silicon based materials [9], lithium alloy materials, and transition metal oxides [10].

As one of the transition metal oxides, $\mathrm{CuO}$ has attracted extensive attention because of its natural abundance, low cost, and ecofriendliness [11, 12], and it has a high theoretical capacity of $674 \mathrm{mAhg}^{-1}$, which is almost two times that of graphite. Same as the other transition metal oxides, it suffers from the large volume expansion and agglomeration during the discharge-charge process, which results in poor conductivity, rapid capacity fading, and poor cycle performance [13]. Some strategies have been made to resolve these issues significantly $[14,15]$. It is reported that the $\mathrm{CuO}$ with various nanostructures can effectively alleviate these drawbacks, such as 0D nanoparticles [16], 1D nanowires [17],
2D nanoplates [18], and 3D nanoflowers [19]. Recently, 1D nanowires have shown great potential application in lithium ion batteries due to their large specific surface area and the porous nanostructures. It can provide short diffusion path lengths for lithium ion transport to improve the electrical conductivity and relieve the volume expansion [20, 21].

Herein, twist-shaped $\mathrm{CuO}$ nanowires were synthesized by two-step method consisting of solution reaction and then heat treatment for the $\mathrm{Cu}(\mathrm{OH})_{2}$ precursor at different temperatures $\left(300^{\circ} \mathrm{C}, 400^{\circ} \mathrm{C}\right.$, and $\left.500^{\circ} \mathrm{C}\right)$ in air. The asprepared $\mathrm{CuO}$ nanowires exhibited enhanced lithium storage capacity and good cyclic performance as anode materials for lithium ion batteries.

\section{Experimental}

2.1. Preparation of Materials. All reagents were of analytical grade and directly used without further purification. In the typical synthesis process, $0.302 \mathrm{~g}$ of $\mathrm{Cu}\left(\mathrm{NO}_{3}\right)_{2} \cdot 3 \mathrm{H}_{2} \mathrm{O}$ and $5 \mathrm{~mL}$ of $\mathrm{H}_{2} \mathrm{O}_{2}$ were dissolved in $50 \mathrm{~mL}$ of deionized water under stirring constantly at room temperature for $15 \mathrm{~min}$. Then, $50 \mathrm{~mL}$ of $\mathrm{NaOH}(0.15 \mathrm{M})$ aqueous solution was added to the above solution under mild mechanical stirring and kept for another $30 \mathrm{~min}$. Next, the resulting samples were collected and washed and centrifuged with deionized water 
and ethanol for several times and then dried at $60^{\circ} \mathrm{C}$ for a night in air. Finally, the $\mathrm{CuO}$ nanowires were obtained by annealing at $300^{\circ} \mathrm{C}, 400^{\circ} \mathrm{C}$, and $500^{\circ} \mathrm{C}$ in air for $20 \mathrm{~min}$ and named as $\mathrm{CuO}-300^{\circ} \mathrm{C}, \mathrm{CuO}-400^{\circ} \mathrm{C}$, and $\mathrm{CuO}-500^{\circ} \mathrm{C}$, respectively.

2.2. Structure and Morphology Characterization. X-ray powder diffraction patterns were collected with a TD-3500 Xray diffractometer equipped with $\mathrm{Cu} / \mathrm{Ka}$ radiation $(\lambda=$ $0.154056 \mathrm{~nm}$ ); the collection angles were set to $10^{\circ}$ to $80^{\circ}$ with a scanning rate of $0.07^{\circ} \mathrm{s}^{-1}$. The morphology and microstructure of the samples were investigated by scanning transmission electron microscopy (TEM-2100).

2.3. Electrochemical Measurements. Electrochemical experiments were carried out in 2032 coin-type cells. The working electrodes were prepared by mixing the active material $(\mathrm{CuO}$ nanowires), acetylene black, and polyvinylidene fluoride (PVDF) with a weight ratio of $80: 10: 10$ in 1-methyl-2pyrrolidinone (NMP) to form homogeneous slurry and the slurries were uniformly coated on the copper foil and finally dried at $100^{\circ} \mathrm{C}$ under vacuum for 12 hours; the total mass loading of the electrode is about $3 \mathrm{mg}$. The pure lithium sheet was as the counter and reference electrode. The electrolyte was $1 \mathrm{M} \mathrm{LiPF}_{6}$ in ethylene carbonate (EC) and dimethyl carbonate (DMC) (1:1 by volume). All the cells were assembled in an argon-filled glovebox with the content of moisture and oxygen below $0.1 \mathrm{ppm}$.

Cyclic voltammetry (CV) and electrochemical impedance spectra (EIS) measurements were performed using $\mathrm{CHI} 760 \mathrm{E}$ electrochemistry workstation. The $\mathrm{CV}$ curves were obtained at a scan rate of $0.2 \mathrm{mV} / \mathrm{s}$ and the EIS plots were conducted in the frequency range from $100 \mathrm{kHz}$ to $0.01 \mathrm{~Hz}$. The galvanostatic charge-discharge tests were recorded on a Battery Testing System (Neware BTS-610) at the current density of $100 \mathrm{~mA} \mathrm{~g}^{-1}$ in the voltage range of 0.01 to $3.0 \mathrm{~V}$.

\section{Results and Discussion}

The schematic growth progress for the formation of twistshaped $\mathrm{CuO}$ nanowires via a typical solution reaction and then heat treatment method is shown in Figure 1. When $\mathrm{Cu}\left(\mathrm{NO}_{3}\right)_{2} \cdot 3 \mathrm{H}_{2} \mathrm{O}$ and $\mathrm{H}_{2} \mathrm{O}_{2}$ solution were mixed under stirring constantly at room temperature, a blue solution was obtained. After $15 \mathrm{~min}, \mathrm{NaOH}$ was added to the above solution, immediately resulting in a black turbid solution and forming numerous black $\mathrm{Cu}(\mathrm{OH})_{2}$ precipitates. With increasing reaction time, the $\mathrm{Cu}(\mathrm{OH})_{2}$ further aged and finally formed individual nanowire structures. Lastly, the twist-shaped $\mathrm{CuO}$ nanowires were obtained by annealing at temperature of $300-500^{\circ} \mathrm{C}$.

The morphology and structure of twist-shaped $\mathrm{CuO}$ nanowires $\left(500^{\circ} \mathrm{C}\right)$ were characterized by TEM. Figure 2(a) confirmed that the samples were a uniform nanowires' structure with a length of $0.75-2.7 \mu \mathrm{m}$. From the enlarged TEM image of samples in Figure 2(b), we could further see that the porous structure-like Chinese hemp flowers rope consisted of several twist-shaped nanowires with a width of
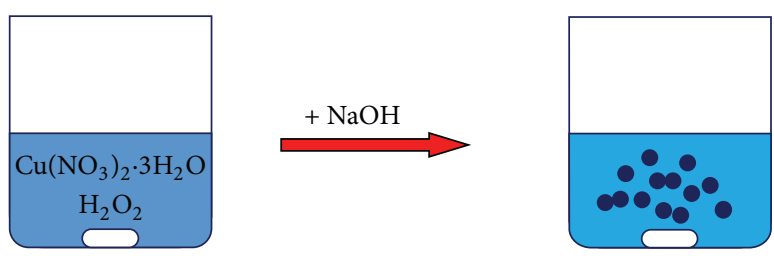

- $\mathrm{Cu}(\mathrm{OH})_{2}$ nucleuses

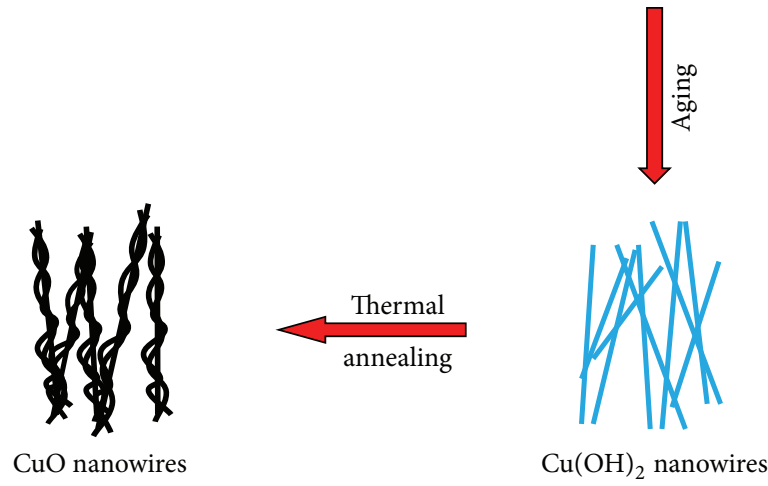

FIgURE 1: Schematic illustration of twist-shaped $\mathrm{CuO}$ nanowires.

about $20-75 \mathrm{~nm}$ and pores ranging from a few to a few tens of nanometers in diameter, which was beneficial to the intercalation of extra lithium and shortened the path of lithium ion transport during the charge-discharge process. The electron diffraction pattern of twist-shaped $\mathrm{CuO}$ nanowires $\left(500^{\circ} \mathrm{C}\right)$ was shown in inset of Figure 2(b).

The crystal structures of the samples were further studied by powder X-ray diffraction in Figure 3. Apparently, the diffraction peaks of $\mathrm{Cu}(\mathrm{OH})_{2}$ nanowires at different angles were like high pure crystal without other peaks compared with the standard card of $\mathrm{Cu}(\mathrm{OH})_{2}$ (JCPDS 13-0420). Meanwhile, $\mathrm{CuO}-300^{\circ} \mathrm{C}, \mathrm{CuO}-400^{\circ} \mathrm{C}$, and $\mathrm{CuO}-500^{\circ} \mathrm{C}$ nanowires were also consistent with the standard card of $\mathrm{CuO}$ (JCPDS 48-1548), indicating that $\mathrm{Cu}(\mathrm{OH})_{2}$ nanowires had transformed to monoclinic crystal $\mathrm{CuO}$ nanowires. Besides, the order of the full-width-at-half-maximum (FWHM) of XRD peaks for three $\mathrm{CuO}$ samples was $0.484^{\circ}\left(\mathrm{CuO}-500^{\circ} \mathrm{C}\right)<$ $0.593^{\circ}\left(\mathrm{CuO}-400^{\circ} \mathrm{C}\right)<0.851^{\circ}\left(\mathrm{CuO}-300^{\circ} \mathrm{C}\right)$, which confirmed that the $\mathrm{CuO}-500^{\circ} \mathrm{C}$ nanowires had better pure crystallinity than others.

In order to investigate the performance of twist-shaped $\mathrm{CuO}$ nanowires, electrochemical characterization was conducted based on 2032 coin-type cells with pure lithium sheet as the counter electrode. The cyclic voltammetry curves of the $\mathrm{CuO}-500^{\circ} \mathrm{C}$ nanowires anode for the 1 st, $2 \mathrm{nd}$, and $3 \mathrm{rd}$ cycles in the potential range from $0 \mathrm{~V}$ to $3 \mathrm{~V}$ (versus $\mathrm{Li}^{+} / \mathrm{Li}$ ) at a scan rate of $0.2 \mathrm{mV} \mathrm{s}^{-1}$ were shown in Figure 4(a). In the first cathodic process, there were two peaks located at around $0.69 \mathrm{~V}$ and $0.93 \mathrm{~V}$, which might be ascribed to the formation of a solid electrolyte interface (SEI) layer and the reduction of $\mathrm{CuO}$ to $\mathrm{Cu}$, respectively [22]. In the first anodic process, two oxidation peaks at $0.81 \mathrm{~V}$ and $2.48 \mathrm{~V}$ were attributed to the oxidation of metallic $\mathrm{Cu}$ to $\mathrm{Cu}_{2} \mathrm{O}$ and the oxidation of $\mathrm{Cu}_{2} \mathrm{O}$ to $\mathrm{CuO}$, respectively [23]. In subsequent cycles, the cathodic peaks shifted to $1.09 \mathrm{~V}$ and $0.61 \mathrm{~V}$ due 


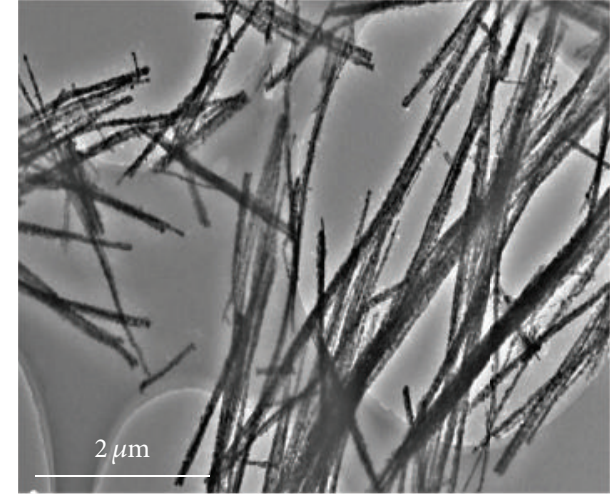

(a)

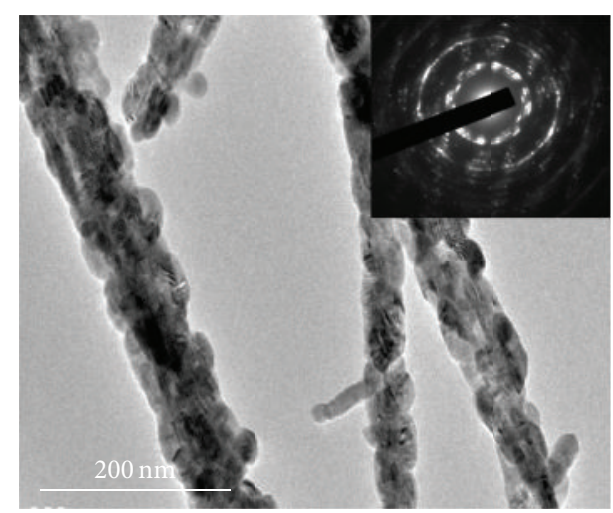

(b)

FIgure 2: (a) Low-resolution TEM of twist-shaped $\mathrm{CuO}$ nanowires $\left(500^{\circ} \mathrm{C}\right)$ and (b) high-resolution TEM of twist-shaped CuO nanowires $\left(500^{\circ} \mathrm{C}\right)$. The inset presents $\mathrm{SAED}$ pattern of $\mathrm{CuO}$ nanowires $\left(500^{\circ} \mathrm{C}\right)$.

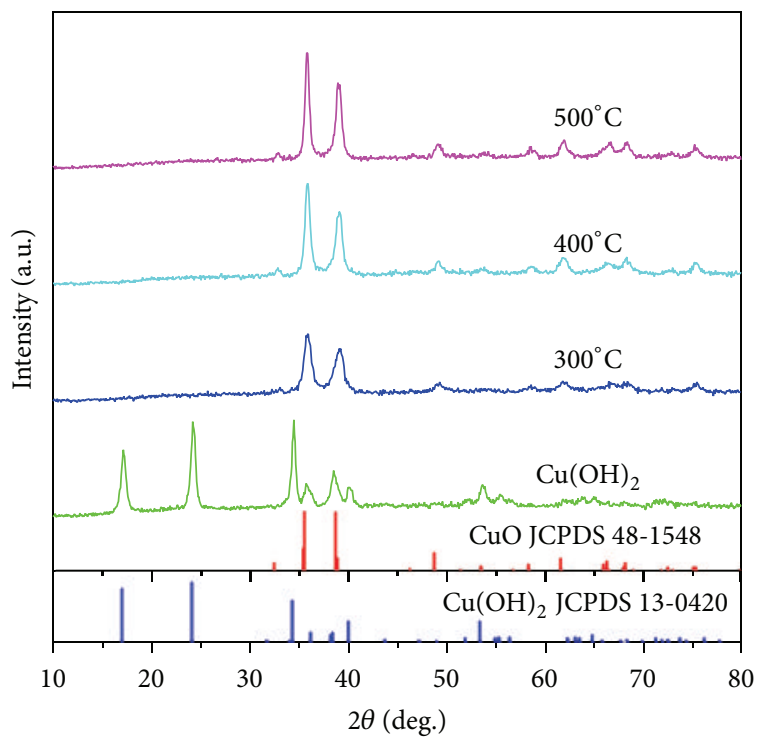

FIGURE 3: XRD patterns of the as-prepared $\mathrm{Cu}(\mathrm{OH})_{2}$ nanowires and $\mathrm{CuO}-300^{\circ} \mathrm{C}, \mathrm{CuO}-400^{\circ} \mathrm{C}$, and $\mathrm{CuO}-500^{\circ} \mathrm{C}$ nanowires.

to the structure modification after the first cycle [18], and the anodic peaks overlapped very well, suggesting that the electrochemical reversibility of $\mathrm{CuO}$ tended to be more stable.

Figure 4(b) presented the galvanostatic discharge-charge profiles of $\mathrm{CuO}-500^{\circ} \mathrm{C}$ nanowires at the current density of $100 \mathrm{mAg}^{-1}$ in the voltage of $0 \sim 3.0 \mathrm{~V}$. In the first discharge profile, two obvious sloping potential plateaus located at 1.6$1.15 \mathrm{~V}$ and $1.0-1.25 \mathrm{~V}$ were observed. The first long voltage plateau $(1.6-1.15 \mathrm{~V})$ implied that the lithium insertion to $\mathrm{CuO}$ was to form $\mathrm{Cu}$ and the second voltage plateau at 1.0$1.25 \mathrm{~V}$ was ascribed to the formation of a solid electrolyte interface (SEI) layer [16, 24]. In the following charge profile, an unobvious voltage plateau at around $2.41 \mathrm{~V}$ represented the oxidation of metallic $\mathrm{Cu}$ to $\mathrm{CuO}$ [23], which was in good agreement with the $\mathrm{CV}$ results. In the first cycle, the discharge capacity of $\mathrm{CuO}-500^{\circ} \mathrm{C}$ nanowires was about $983 \mathrm{mAh} \mathrm{g}^{-1}$; however, the first charge capacity dramatically decreased to $496 \mathrm{mAh} \mathrm{g}^{-1}$ corresponding to low coulombic efficiency of $50 \%$. The high capacity loss was believed to originate from the decomposition of electrolyte and the formation of solid electrolyte interface (SEI) layer on the electrode surface $[25,26]$. At the second cycle, the discharge capacity was $495 \mathrm{mAh} \mathrm{g}^{-1}$, with coulombic efficiency of $95.2 \%$, and $482 \mathrm{mAh} \mathrm{g}^{-1}$ and $96.5 \%$ at the third cycle, which indicated that the reversible performance increased.

The cycling performances of twist-shaped $\mathrm{CuO}$ nanowires of different temperature and their corresponding coulombic efficiencies at the current density of $100 \mathrm{~mA} \mathrm{~g}^{-1}$ were shown in Figure 4(c). It can be seen that the $\mathrm{CuO}$ $500^{\circ} \mathrm{C}$ nanowires showed the highest capacity of $983 \mathrm{mAh} \mathrm{g}^{-1}$ for the first cycle, the $\mathrm{CuO}-400^{\circ} \mathrm{C}$ presented lower capacity of $956 \mathrm{mAh} \mathrm{g}^{-1}$, and the $\mathrm{CuO}-300^{\circ} \mathrm{C}$ presented the lowest capacity of $948 \mathrm{mAh} \mathrm{g}^{-1}$. Although all samples had a higher capacity than the theoretical capacity of $\mathrm{CuO}\left(670 \mathrm{mAh} \mathrm{g}^{-1}\right)$ for the first cycle, they have a low coulombic efficiency, which is attributed to the formation of SEI layer on the electrode surface, large volume expansion, and electrode decomposition during the charge-discharge process [12, 27]. Even after 50 cycles, the discharge capacity of $320 \mathrm{mAh} \mathrm{g}^{-1}$ of $\mathrm{CuO}-500^{\circ} \mathrm{C}$ was much higher than $203 \mathrm{mAh} \mathrm{g}^{-1}$ of $\mathrm{CuO}-$ $400^{\circ} \mathrm{C}$ and $133 \mathrm{mAh} \mathrm{g}^{-1}$ of $\mathrm{CuO}-300^{\circ} \mathrm{C}$. It is also better than that of spherical $\mathrm{CuO}$ nanoparticles reported by Zhang et al., $300 \mathrm{mAh} \mathrm{g}^{-1}$ after 30 charge/discharge cycles [28]. Therefore, $\mathrm{CuO}-500^{\circ} \mathrm{C}$ nanowires exhibited the most excellent performance, which indicated that high temperature calcination was beneficial to the lithium storage. In addition, all samples possessed a high coulombic efficiency of $98 \%$ except the first several cycles.

In order to verify the remarkable cycle performance of $\mathrm{CuO}$ nanowires electrodes, electrochemical impedance spectrum (EIS) was performed on the cell. Electrochemical impedance spectrum (EIS), in Figure 4(d), consisted of a small semicircle at the high-medium frequency region and a long line at the low-medium frequency region. In the highmedium frequency, semicircle represented the electric contact and charge-transfer resistance and, in the low-medium frequency, the slope of line associated with lithium ion diffusion activity. Obviously, we could observe that the diameter 


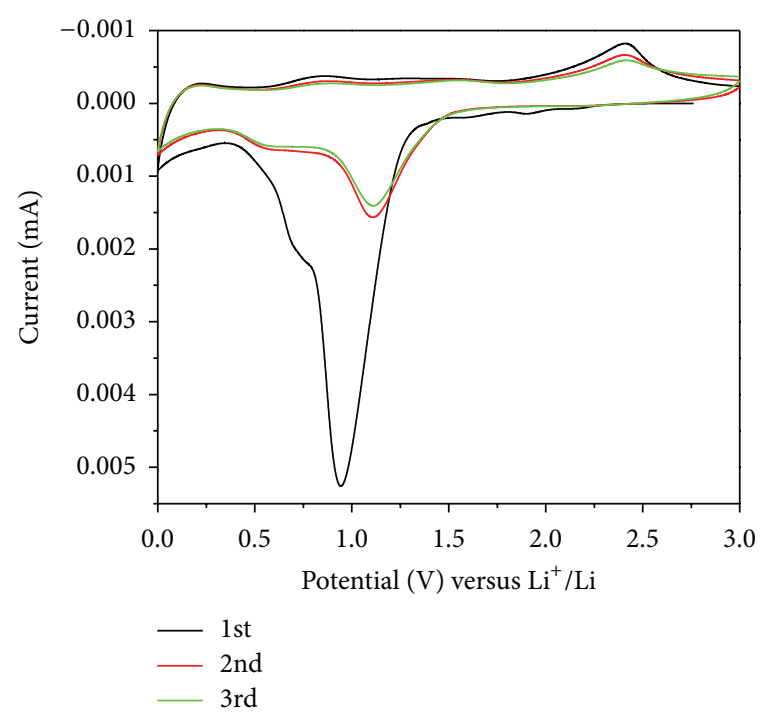

(a)

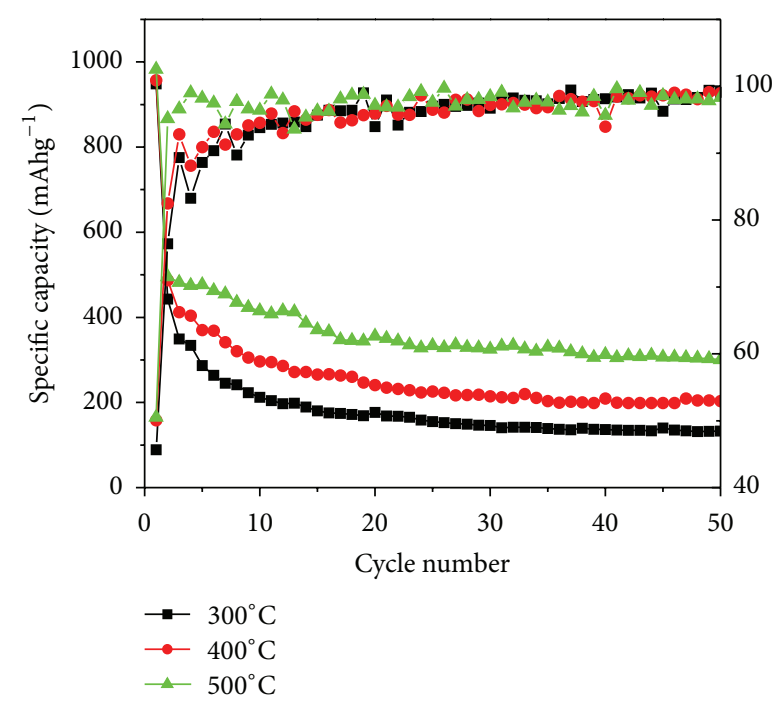

(c)

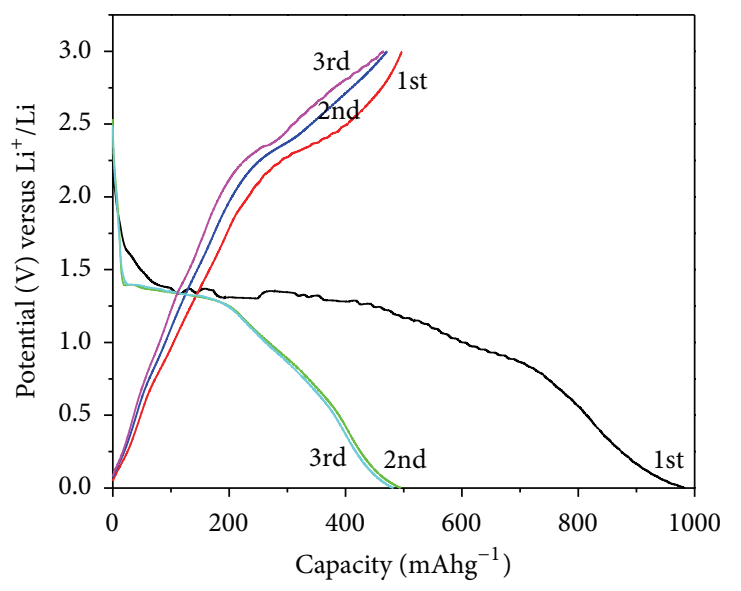

(b)

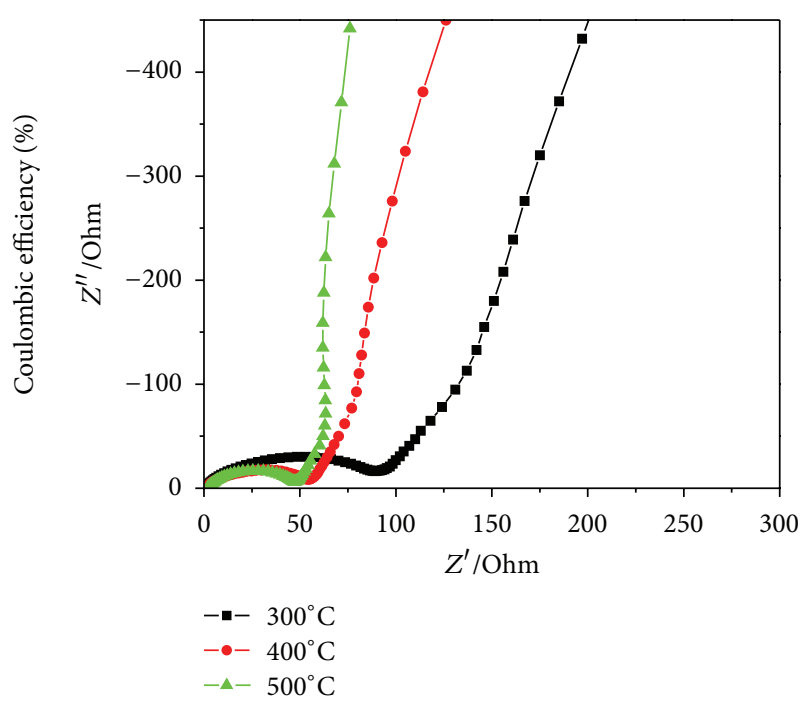

(d)

Figure 4: (a) Cyclic voltammetry curves of $\mathrm{CuO}-500^{\circ} \mathrm{C}$ nanowires in the 1st, 2nd, and 3rd cycles. (b) Galvanostatic discharge-charge profiles in the 1st, $2 \mathrm{nd}$, and $3 \mathrm{rd}$ cycles of $\mathrm{CuO}-500^{\circ} \mathrm{C}$ nanowires at the current density of $100 \mathrm{~mA} \mathrm{~g}^{-1}$. (c) Cycling performances of CuO-300 $0^{\circ} \mathrm{C}, \mathrm{CuO}-$ $400^{\circ} \mathrm{C}$, and $\mathrm{CuO}-500^{\circ} \mathrm{C}$ at the current density of $100 \mathrm{~mA} \mathrm{~g}^{-1}$. (d) Electrochemical impedance spectra plots of CuO nanowires electrodes over the frequency range of $100 \mathrm{kHz}$ and $0.01 \mathrm{~Hz}$.

of the semicircle of $\mathrm{CuO}-500^{\circ} \mathrm{C}$ was smaller than that of $\mathrm{CuO}-400^{\circ} \mathrm{C}$ and $\mathrm{CuO}-300^{\circ} \mathrm{C}$, suggesting that $\mathrm{CuO}-500^{\circ} \mathrm{C}$ had the lowest electric contact and charge-transfer resistance. What was more, the slope of line of $\mathrm{CuO}-500^{\circ} \mathrm{C}$ was bigger compared to others, which also verified the front result. Because of better crystallinity at $500^{\circ} \mathrm{C}, \mathrm{CuO}$ at $500^{\circ} \mathrm{C}$ showed more superior electrochemical performance to the other temperatures.

\section{Conclusion}

In this work, twist-shaped $\mathrm{CuO}$ nanowires were successfully synthesized by two-step method consisting of solution reaction and then heat treatment for the $\mathrm{Cu}(\mathrm{OH})_{2}$ precursor at different temperature in air. This method is simple, rapid, green, and of low cost. When evaluated as anode materials for lithium ion batteries, $\mathrm{CuO}-500^{\circ} \mathrm{C}$ nanowires showed a great electrochemical performance, including high discharge capacity and high capacity retention, delivered a high initial discharge capacity of $983 \mathrm{mAhg}^{-1}$ in the first cycle, and maintained a reversible capacity of $320 \mathrm{mAh} \mathrm{g}^{-1}$ over 50 cycles at a current density of $100 \mathrm{~mA} \mathrm{~g}^{-1}$. Thus, 1D twistshaped $\mathrm{CuO}$ nanowires provided a new insight into the development of anode materials for next-generation high performance lithium ion batteries.

\section{Competing Interests}

The authors declare that they have no competing interests. 


\section{Acknowledgments}

This work was financially supported by Basic and Frontier Research Program of Chongqing Municipality (cstc2015jcyjA90020 and cstc2014jcyjA10063), Scientific and Technological Research Program of Chongqing Municipal Education Commission (KJ1501101, KJ1500323, and KJ1501116), Introduction of Talent Project of Chongqing University of Arts and Sciences (R2013CJ06), China Postdoctoral Science Foundation (2015M582499), Postdoctoral Special Foundation of Chongqing (Xm2015064), Project of Chongqing Normal University (14XYY025 and 14XLB004), and National Natural Science Foundation of China (51502030).

\section{References}

[1] W. Wei, S. Yang, H. Zhou, I. Lieberwirth, X. Feng, and K. Müllen, "3D graphene foams cross-linked with pre-encapsulated $\mathrm{Fe}_{3} \mathrm{O}_{4}$ nanospheres for enhanced lithium storage," Advanced Materials, vol. 25, no. 21, pp. 2909-2914, 2013.

[2] C. Marino, A. Debenedetti, B. Fraisse, F. Favier, and L. Monconduit, "Activated-phosphorus as new electrode material for Li-ion batteries," Electrochemistry Communications, vol. 13, no. 4, pp. 346-349, 2011.

[3] Z. Cao, Y. Ding, J. Zhang et al., "Submicron peanut-like $\mathrm{MnCO}_{3}$ as an anode material for lithium ion batteries," RSC Advances, vol. 5, no. 69, pp. 56299-56303, 2015.

[4] J.-Y. Liao, D. Higgins, G. Lui, V. Chabot, X. Xiao, and Z. Chen, "Multifunctional $\mathrm{TiO}_{2}-\mathrm{C} / \mathrm{MnO}_{2}$ core-double-shell nanowire arrays as high-performance $3 \mathrm{D}$ electrodes for lithium ion batteries," Nano Letters, vol. 13, no. 11, pp. 5467-5473, 2013.

[5] A. Bhaskar, M. Deepa, T. N. Rao, and U. V. Varadaraju, "Enhanced nanoscale conduction capability of a $\mathrm{MoO}_{2} / \mathrm{Gra}$ phene composite for high performance anodes in lithium ion batteries," Journal of Power Sources, vol. 216, pp. 169-178, 2012.

[6] X. Dong, L. Li, C. Zhao, H.-K. Liu, and Z. Guo, "Controllable synthesis of RGO/FexOy nanocomposites as high-performance anode materials for lithium ion batteries," Journal of Materials Chemistry A, vol. 2, no. 25, pp. 9844-9850, 2014.

[7] Z. Bai, N. Fan, C. Sun et al., "Facile synthesis of loaf-like $\mathrm{ZnMn}_{2} \mathrm{O}_{4}$ nanorods and their excellent performance in Li-ion batteries," Nanoscale, vol. 5, no. 6, pp. 2442-2447, 2013.

[8] W. Kang, Y. Tang, W. Li et al., "Porous $\mathrm{CuCo}_{2} \mathrm{O}_{4}$ nanocubes wrapped by reduced graphene oxide as high-performance lithium-ion battery anodes," Nanoscale, vol. 6, no. 12, pp. 65516556, 2014.

[9] S. Jing, H. Jiang, Y. Hu, and C. Li, "Directly grown Si nanowire arrays on $\mathrm{Cu}$ foam with a coral-like surface for lithium-ion batteries," Nanoscale, vol. 6, no. 23, pp. 14441-14445, 2014.

[10] P. Lv, H. Zhao, Z. Zeng, J. Wang, T. Zhang, and X. Li, “Facile preparation and electrochemical properties of carbon coated $\mathrm{Fe}_{3} \mathrm{O}_{4}$ as anode material for lithium-ion batteries," Journal of Power Sources, vol. 259, pp. 92-97, 2014.

[11] J. Pal, C. Mondal, A. K. Sasmal, M. Ganguly, Y. Negishi, and T. Pal, "Account of nitroarene reduction with size- and facetcontrolled $\mathrm{CuO}-\mathrm{MnO}_{2}$ nanocomposites," ACS Applied Materials \& Interfaces, vol. 6, no. 12, pp. 9173-9184, 2014.

[12] Q. Wang, J. Zhao, W. Shan, X. Xia, L. Xing, and X. Xue, "CuO nanorods/graphene nanocomposites for high-performance lithium-ion battery anodes," Journal of Alloys and Compounds, vol. 590, pp. 424-427, 2014.
[13] S. Yuan, X.-L. Huang, D.-L. Ma, H.-G. Wang, F.-Z. Meng, and $\mathrm{X}$.-B. Zhang, "Engraving copper foil to give large-scale binderfree porous $\mathrm{CuO}$ arrays for a high-performance sodium-ion battery anode," Advanced Materials, vol. 26, no. 14, pp. 22732279, 2014.

[14] Y. Xu, R. Yi, B. Yuan et al., "High capacity $\mathrm{MoO}_{2}$ /graphite oxide composite anode for lithium-ion batteries," Journal of Physical Chemistry Letters, vol. 3, no. 3, pp. 309-314, 2012.

[15] K. Zhang, W. Zhao, J.-T. Lee, G. Jang, X. Shi, and J. H. Park, "A magnetic field assisted self-assembly strategy towards strongly coupled $\mathrm{Fe}_{3} \mathrm{O}_{4}$ nanocrystal/rGO paper for high-performance lithium ion batteries," Journal of Materials Chemistry A, vol. 2, no. 25, pp. 9636-9644, 2014.

[16] S. He, J. Li, J. Wang, G. Yang, and Z. Qiao, "Facile synthesis and lithium storage performance of hollow $\mathrm{CuO}$ microspheres," Materials Letters, vol. 129, pp. 5-7, 2014.

[17] L. Wang, K. Zhang, Z. Hu, W. Duan, F. Cheng, and J. Chen, "Porous $\mathrm{CuO}$ nanowires as the anode of rechargeable Na-ion batteries," Nano Research, vol. 7, no. 2, pp. 199-208, 2014.

[18] Y. Liu, Y. Qiao, W. Zhang et al., "Facile fabrication of $\mathrm{CuO}$ nanosheets on $\mathrm{Cu}$ substrate as anode materials for electrochemical energy storage," Journal of Alloys and Compounds, vol. 586, pp. 208-215, 2014.

[19] Z. Hu and H. Liu, "Three-dimensional $\mathrm{CuO}$ microflowers as anode materials for Li-ion batteries," Ceramics International, vol. 41, no. 6, pp. 8257-8260, 2015.

[20] C. Wu, X. Li, W. Li et al., " $\mathrm{Fe}_{2} \mathrm{O}_{3}$ nanorods/carbon nanofibers composite: preparation and performance as anode of high rate lithium ion battery," Journal of Power Sources, vol. 251, pp. 85-91, 2014.

[21] Q. Zhou, Z. Zhao, Z. Wang et al., "Low temperature plasma synthesis of mesoporous $\mathrm{Fe}_{3} \mathrm{O}_{4}$ nanorods grafted on reduced graphene oxide for high performance lithium storage," Nanoscale, vol. 6, no. 4, pp. 2286-2291, 2014.

[22] J. Wang, Q. Zhang, X. Li et al., “Three-dimensional hierarchical $\mathrm{Co}_{3} \mathrm{O}_{4} / \mathrm{CuO}$ nanowire heterostructure arrays on nickel foam for high-performance lithium ion batteries," Nano Energy, vol. 6, pp. 19-26, 2014.

[23] C. Wang, Q. Li, F. Wang et al., "Morphology-dependent performance of $\mathrm{CuO}$ anodes via facile and controllable synthesis for lithium-ion batteries," ACS Applied Materials and Interfaces, vol. 6, no. 2, pp. 1243-1250, 2014.

[24] A. Li, H. Song, W. Wan, J. Zhou, and X. Chen, "Copper oxide nanowire arrays synthesized by in-situ thermal oxidation as an anode material for lithium-ion batteries," Electrochimica Acta, vol. 132, pp. 42-48, 2014.

[25] J. Guo, L. Ma, X. Zhang, Y. Zhang, and L. Tang, "Mesoporous $\mathrm{CuO}$ xerogels constructed by nanorods for high-performance lithium storage," Materials Letters, vol. 118, pp. 142-145, 2014.

[26] L. Feng, Z. Xuan, Y. Bai et al., "Preparation of octahedral CuO micro/nanocrystals and electrochemical performance as anode for lithium-ion battery," Journal of Alloys and Compounds, vol. 600, pp. 162-167, 2014.

[27] C. Wang, J. Xu, R. Ma, and M.-F. Yuen, "Facile synthesis of $\mathrm{CuO}$ nanoneedle electrodes for high-performance lithium-ion batteries," Materials Chemistry and Physics, vol. 148, no. 1-2, pp. 411-415, 2014.

[28] X. Zhang, G. Wang, X. Liu, and H. Wu, "Synthesis and electrochemical properties of $\mathrm{CuO}$ nanobelts," Materials Chemistry and Physics, vol. 112, no. 3, pp. 726-729, 2008. 

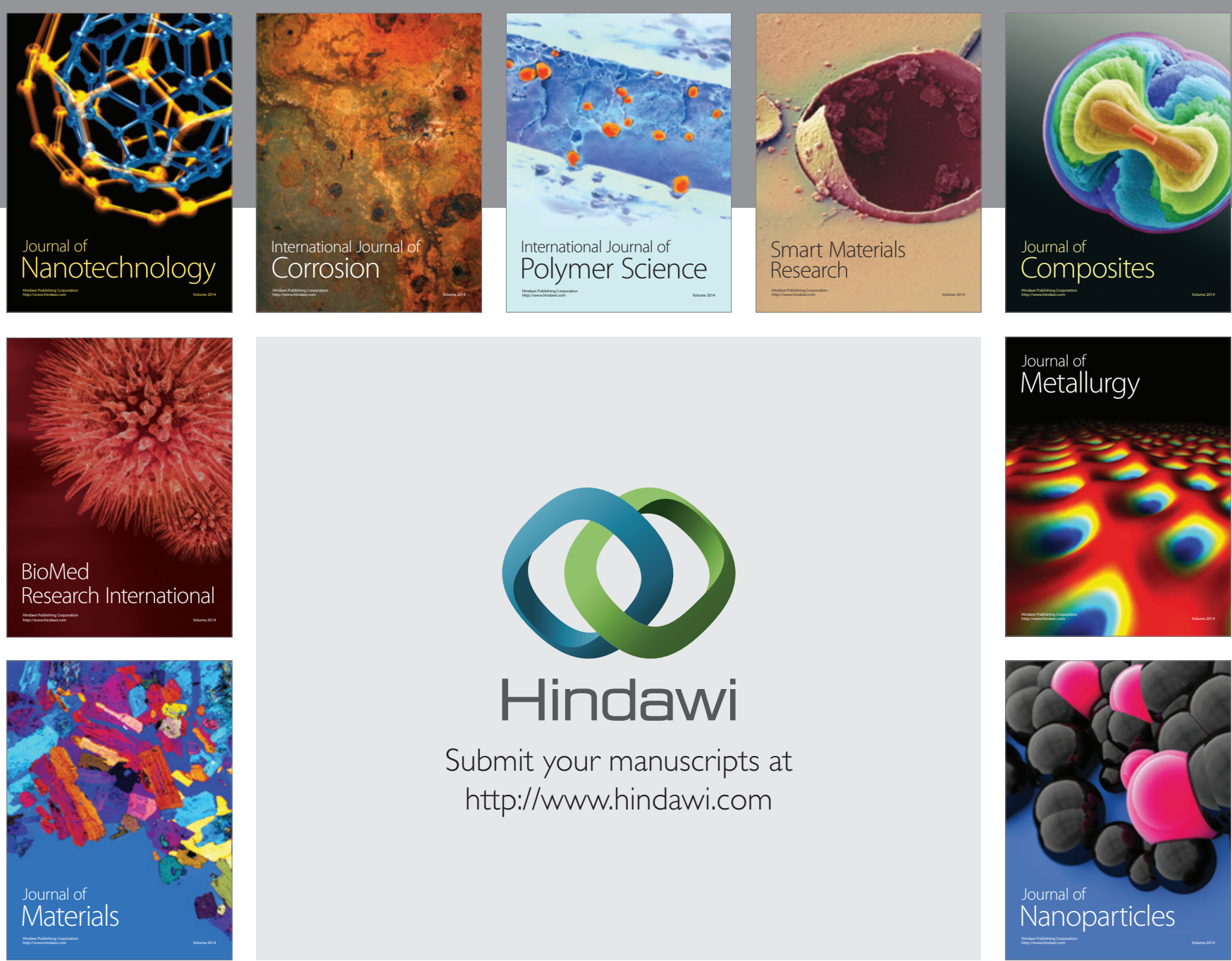

\section{Hindawi}

Submit your manuscripts at

http://www.hindawi.com

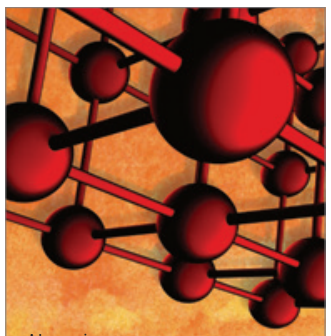

Materials Science and Engineering
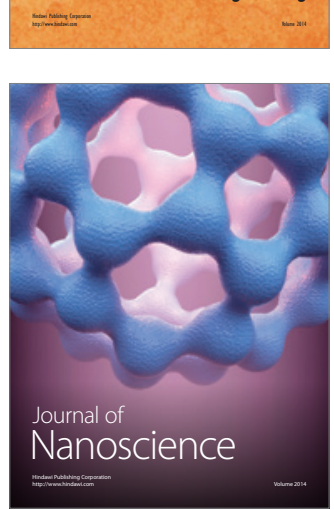
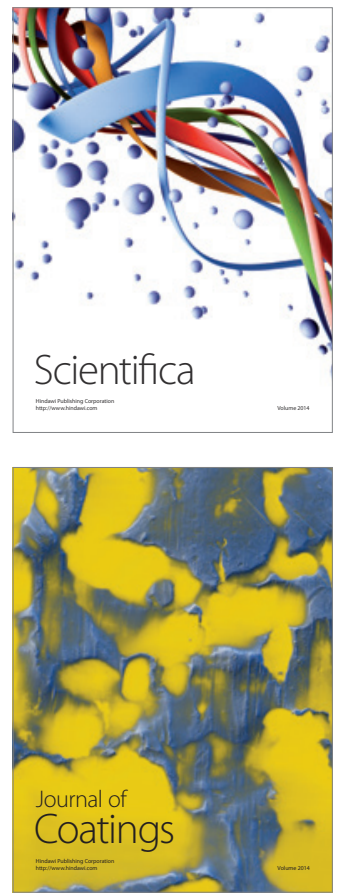
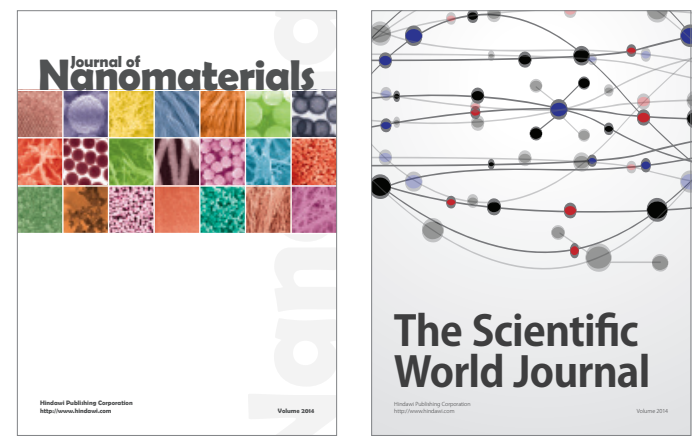

The Scientific World Journal
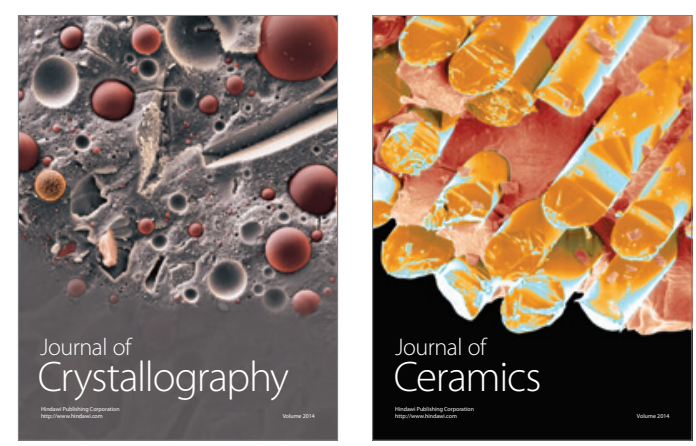
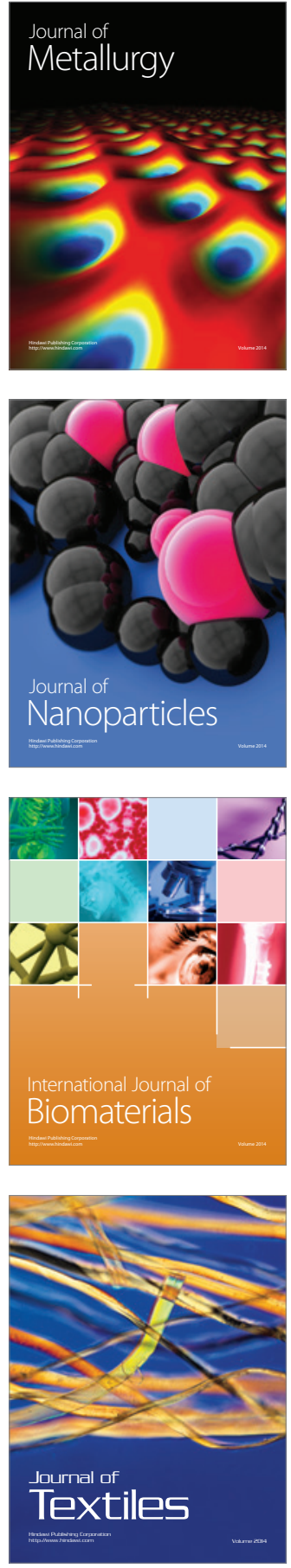